\title{
Do visual field deficits exacerbate visuo-spatial neglect?
}

\author{
P W Halligan, J C Marshall, D T Wade
}

\begin{abstract}
A significant association between visual field deficits (VFD) and visuo-spatial neglect is well established, although cases of double-dissociation between the two conditions are not uncommon. It has been argued that VFD typically exacerbates the behavioural manifestations of neglect. We examined a series of 51 patients with unilateral right-hemisphere stroke for the presence of visual field deficit and visuo-spatial neglect. Patients were assigned to the neglect group $(\mathbf{N}+)$ or the non-neglect group $(\mathrm{N}-)$ on the basis of their aggregate scores on the recently standardised Behavioural Inattention Test (BIT). The association between neglect and VFD was confirmed. Four groups of eight patients $(\mathbf{N}+, \mathbf{V F D}+; \mathbf{N}+, \mathbf{V F D}-; \mathbf{N}-$, VFD + ; $\mathbf{N}_{-}, \mathbf{V F D}-$ ) were then selected from the initial sample so that they were matched for age, IQ, and days post onset of stroke. Within the neglect groups, the severity of neglect did not differ significantly between those patients with and without VFD; within the non-neglect groups, scores on subtests of the BIT likewise did not differ (with the sole exception of Letter Cancellation) between the VFD + and the VFD - subgroups. It was concluded that visual field deficits do not exacerbate neglect, and that poor functional recovery in many patients with VFDs is due to the association of sensory loss with the underlying causal factor of neglect.
\end{abstract}

Visual field deficits (VFD) are commonly found after stroke, ${ }^{1}$ and provide unequivocal evidence for injury to the optic tract, the geniculostriate pathway, or striate cortex. Although some patients with homonymous hemianopia initially collide with objects or manifest reading difficulties on the affected side, most appear to compensate by making appropriate head and eye movements; ${ }^{23}$ such adaptations include directing longer fixations towards the hemispace contralateral to injury..$^{3-5}$ Oculographic studies have shown that hemianopic patients may employ a series of stepwise saccadic eye movements which allow them to find and fixate objects located initially in the blind hemifield. ${ }^{3}$ These compensatory eye movements may be directed by extrageniculate striate pathways. ${ }^{3}$

Despite the apparent ability of hemianopic patients to compensate for their visual loss, many investigations of recovery from stroke ${ }^{67}$ describe the presence of visual field deficits as a negative prognostic factor. Studies by Haerer ${ }^{8}$ and Feigenson et $a l^{9}$ indicate that a visual field deficit is associated with poor functional recovery following stroke. Wade et $a l^{10}$ found that hemianopia was one of five critical variables selected by stepwise multiple regression analysis to identify variables predictive of Activities of Daily Living (ADL) status at six months.

Although these studies suggest that VFD has deleterious effects on perceptual tasks and rehabilitation success, a closer examination of the evidence indicates that visual field deficits per se might not necessarily constitute a negative prognostic factor. ${ }^{11}$ Allen ${ }^{12}$ investigated 148 consecutively admitted stroke patients; in this sample, hemianopia alone was associated with $100^{\circ}$ o success in functional recovery, whereas a combination of hemianopia with 1) a higher level functional deficit (aphasia or neglect or proprioceptive loss); 2) hemiplegia; or 3) both higher level deficit and hemiplegia, resulted in a significant reduction in successful outcome by $39 \%, 60 \%$ and $83 \%$ respectively.

When VFD has been singled out as a poor prognostic factor, there has been little control over the effects of associated disturbances in visuo-spatial functioning. The large-scale study by Feigensen et $a l^{9}$ referred to the "clinical impression" that many patients with homonymous hemianopia also had visual neglect or anosognosia. Visual neglect or hemi-inattention has been repeatedly found in association with poor prognosis ${ }^{1314}$ and lack of rehabilitation success. ${ }^{15}$ It may thus be the case that other visuo-spatial disorders commonly associated with "low level" visual impairment are responsible for poor recovery. ${ }^{914-17}$

Although the two conditions are distinct, several authors have suggested "that the presence of a sensory field loss plays a strong role in the relationship between severity of visual hemi-neglect and various parameters of eye movement behaviour". ${ }^{18}$ Experimental studies of visuo-spatial performance after stroke have often been interpreted in this fashion. ${ }^{19-22}$ Thus $\operatorname{Ogden}^{23}$ claims that "although VFDs do not cause neglect they may well exacerbate it." This conclusion is supported by Weintraub and Mesulam ${ }^{24}$ who claim that "a visual field deficit may contribute to a general increase in the number of target omissions but is not a necessary condi- 
tion for the emergence of neglect." Yet many studies describing the effects of VFDs are difficult to evaluate precisely because of the close relationship with spatial disorders such as visual neglect; the absence of any widely accepted standardised measure of visual neglect compounds the problem still further. ${ }^{25}$ Gouvier et al ${ }^{26}$ note that "the significance of a field cut is often exacerbated by the presence of hemi-inattentional deficits."

Using the recently standardised Behavioural Inattention Test $(B I T)^{27}$ we examined the relationships between VFD and visual neglect in a group of stroke patients. Two main questions are addressed: 1) what is the association between visual field deficits and visual neglect? 2) Does the presence of a visual field deficit exacerbate neglect?

\section{Patients and methods}

Fifty one patients with right brain damage (RBD) with a diagnosis of stroke were recruited from admissions to Rivermead Rehabilitation Centre, Oxford. Patients were diagnosed according to physical signs and history, confirmed in 20 cases by computerised tomography (CT). All patients were right handed and were capable of comprehending the task requirements. The majority of patients were tested within two weeks after admission; mean days post-onset of stroke was 87 (with a SD of 81 and a range of 12 to 366 ). On admission each patient was given a complete neurological examination which included the confrontational assessment of visual fields; patients were then classified as having either full fields, ${ }^{27}$ homonymous hemianopia, ${ }^{20}$ or inferior quadrantanopia. ${ }^{4}$

All patients were administered a comprehensive visual neglect battery of six pencil and paper tests from the BIT. ${ }^{27}$ Premorbid intellectual functioning was estimated from the National Adult Reading Test; ${ }^{28}$ for patients with neglect, a modified format was used to minimise the effects of left-sided inattention. Eye and head movements were not restricted during testing for neglect, but moving the stimulus paper was not permitted; test material was centred on the patients' midsagittal plane. The six tests were:

Line crossing This task, adapted from Albert, ${ }^{29}$ consists of 40 short lines randomly positioned over the page. The patient is requested to cross out all the lines; maximum score is 36 (the four central lines are not scored). The cut-off score for a diagnosis of impairment is 34 .

Letter cancellation 170 upper case letters arranged in five rows are presented. Forty letter targets comprising $40 \%$ of the total stimuli are positioned so that approximately equal numbers appear on either side of the midplane. The patient is instructed to cross out all the target stimuli; maximum score is 40. The cut-off is 32 .

Star cancellation The stimuli are 52 large stars, 13 letters, 10 short words, interspersed with 56 smaller stars. The patient is instructed to cross out all the small stars. Two of the central small stars are used for demonstration, and the maximum score is thus 54 . The cutoff is 51 .

Figure and shape copying The patient copies three outline drawings of a) a four-pointed star, b) a cube and c) a daisy. In part two a group of three simple geometric shapes presented on a separate stimulus sheet is copied. The presence of neglect is defined as the omission of any major part of a lateralised subcomponent of the figures; maximum score is four. The cut-off is three.

Line bisection Each patient was presented with three horizontal ( 8 inch/204 mm) black lines presented in a "staircase" fashion across the page. The test is scored by measuring the extent to which the patient's mark deviates from true centre on each line; maximum score is nine. The cut-off is seven.

Representational drawing The patient draws, from memory, a clock-face, a man or woman, and a butterfly. Scoring is the same as for figure copying, with a maximum of three. The cut-off is two.

The diagnosis of visual neglect was calculated from normative data on 50 age-matched control subjects. ${ }^{27}$ The presence of neglect on each of the six tests was defined as the score one point or more below the lowest score achieved by any normal control subject. Aggregate performance on the six tests was used to assess the presence and extent of visual neglect; the cut-off score for normality is $130 / 146$.

\section{Results}

Using the operational definition of neglect described above, 23 of the 51 patients $(45 \%)$ demonstrated neglect (table 1). However, there were eight patients who fell within the neglect classification who did not show visual field deficits, and nine patients who clearly demonstrated visual field deficits but scored well above the cut-off criterion for neglect. These results confirm previous findings of double dissociation between the two disorders. ${ }^{22} 2329$

Table 1 shows that of the 24 patients with visual field deficits (VFD +), 63\% also show neglect; of the patients without sensory loss $(\mathrm{VFD}-)$, only $30 \%$ show neglect. If neglect is taken as the reference criterion, $63 \%$ of the neglect patients $(\mathrm{N}+)$ also have visual field defects; of the patients without neglect $(\mathrm{N}-)$, only $32 \%$ have visual field defects. These contingencies are significant at $\mathrm{p}<0.01$ $\left(\chi^{2}=5.5\right)$; a strong association between the presence of neglect and of VFD is thus confirmed. ${ }^{20-22}$

We now consider the degree of neglect in patients with and without VFD. To evaluate

Table 1 The association between visuo-spatial neglect (N) and visual field deficit (VFD) in a sample of 51 patients with unilateral right-hemisphere stroke

\begin{tabular}{llc}
\hline & $V F D+$ & $V F D-$ \\
\hline $\mathrm{N}+$ & 15 & 8 \\
$\mathrm{~N}-$ & 9 & 19 \\
\hline
\end{tabular}


Table 2 Means (SD) for scores on six neglect tests by normal controls and four patient groups

\begin{tabular}{|c|c|c|c|c|c|c|c|}
\hline & \multirow{2}{*}{$\begin{array}{l}\text { Normal } \\
\text { controls } \\
-\end{array}$} & \multicolumn{2}{|c|}{$V F D+$ patients } & \multicolumn{2}{|c|}{$V F D-$ patients } & \multirow[b]{2}{*}{$F$} & \multirow[b]{2}{*}{$P$} \\
\hline & & $V F D+N+$ & $V F D+N-$ & $V F D-N+$ & $V F D-N-$ & & \\
\hline $\begin{array}{l}\text { Number } \\
\text { Age (years) } \\
\text { IQ } \\
\text { Days Post-stroke }\end{array}$ & $\begin{array}{c}8 \\
66 \cdot 5(3 \cdot 6) \\
111 \cdot 75(5 \cdot 8) \\
-\end{array}$ & $\begin{array}{l}8 \\
61.6(8.4) \\
107.7(10.5) \\
53.0(19.4)\end{array}$ & $\begin{array}{c}8 \\
59 \cdot 4(5 \cdot 4) \\
110 \cdot 5(12 \cdot 9) \\
79 \cdot 1(56 \cdot 4)\end{array}$ & $\begin{array}{c}8 \\
57 \cdot 3(7 \cdot 2) \\
106 \cdot 1(8 \cdot 6) \\
51 \cdot 5(38 \cdot 8)\end{array}$ & $\begin{array}{c}8 \\
54 \cdot 6(11 \cdot 7) \\
113 \cdot 3(6 \cdot 2) \\
85 \cdot 1(28 \cdot 5)\end{array}$ & $\begin{array}{l}2.7 \\
0.72 \\
1.65\end{array}$ & $\begin{array}{l}\text { NS } \\
\text { NS } \\
\text { NS }\end{array}$ \\
\hline $\begin{array}{l}\text { Neglect Tests } \\
\text { Line Crossing } \\
\text { Letter Cancellation } \\
\text { Star Cancellation } \\
\text { Figure Copying } \\
\text { Line Bisection } \\
\text { Rep Drawing } \\
\text { Total }\end{array}$ & $\begin{array}{c}36(0) \\
39(1 \cdot 7) \\
53 \cdot 4(0 \cdot 9) \\
4(-) \\
9(-) \\
3(-) \\
144 \cdot 4(2 \cdot 3)\end{array}$ & $\begin{array}{c}31.3(9.6) \\
23.6(11.2) \\
32.5(15.8) \\
2.3(1.6) \\
4.8(3.7) \\
2.0(1.1) \\
96.4(35.3)\end{array}$ & $\begin{array}{c}35.1(1.8) \\
36.0(1.8) \\
50.6(4.3) \\
3.8(0.4) \\
8.9(0.4) \\
3.0(0) \\
137.5(4.5)\end{array}$ & $\begin{array}{c}26.6(8.5) \\
21.8(10.5) \\
35.0(17.5) \\
2.0(1.6) \\
5.3(3.0) \\
2.1(1.4) \\
92.8(36.6)\end{array}$ & $\begin{array}{c}35.8(0.7) \\
38.8(2.1) \\
52.5(2.3) \\
3.8(0.5) \\
8.5(1.1) \\
3.0(0) \\
142.3(4.4)\end{array}$ & $\begin{array}{c}3.86 \\
11.55 \\
7.88 \\
6.9 \\
7 \cdot 3 \\
3.56 \\
10.0\end{array}$ & $\begin{array}{l}0.03 \\
0.001 \\
0.001 \\
0.001 \\
0.001 \\
0.03 \\
0.001\end{array}$ \\
\hline
\end{tabular}

this relationship patients were again divided into four groups; those with visual field deficits with and without visual neglect and those patients without field deficits with and without visual neglect. As the smallest of these groups (N+VFD - ) contained eight subjects, the same number was selected from each of the three remaining groups; patients were chosen for these three groups such that they did not differ significantly from the reference group $(\mathrm{N}+\mathrm{VFD}-$ ) for age, IQ and number of days post onset of stroke. A sample of normal controls matched for age and IQ was also included for comparison. Of the patients with VFD, two in the $\mathrm{N}+$ group had quadrantanopias and two in the $\mathrm{N}-$ group. The mean, $\mathrm{SD}$, and range of scores for demographic and neuropsychological variables are shown in table 2. One-way analyses of variance were used to assess group differences for each test variable with group membership serving as the independent variable and each of the six neglect tests serving as a dependent variable. Age, days post onset and intellectual functioning did not differ significantly between the five groups. However, there were significant differences in performance between patient groups on all the neglect tests (table 2).

Table 3 shows the number of patients in each of the four groups $(\mathrm{VFD}+\mathrm{N}+$; VFD $+\mathrm{N}-$; $\mathrm{VFD}-\mathrm{N}+; \mathrm{VFD}-\mathrm{N}-$ ) who passed each of the six neglect tests. As found in a previous study, ${ }^{30}$ Star Cancellation is the most sensitive test. Post-hoc comparisons using serial $t$ tests were conducted between all relevant patient and control groups. For the patients with visual field deficits only Line Crossing failed to discriminate between the patients with and without neglect. For the patients without visual field deficits only Representational Drawing failed to discriminate between the patients with and without neglect. The statistical comparisons are shown in table 4a.

For the patients with neglect, no comparison on any test was significant between the groups

Table 3 Number of subjects in the four patient groups who pass each neglect test

\begin{tabular}{lccccc}
\hline Test & & $V F D+N+$ & $V F D+N-$ & $V F D-N+$ & $V F D-N-$ \\
\hline Line Crossing & 1 & $5 / 8$ & $6 / 8$ & $2 / 8$ & $7 / 8$ \\
Letter Cancellation & 2 & $2 / 8$ & $8 / 8$ & $1 / 8$ & $8 / 8$ \\
Star Cancellation & 3 & $0 / 8$ & $5 / 8$ & $0 / 8$ & $6 / 8$ \\
Figure Copying & 4 & $2 / 8$ & $6 / 8$ & $2 / 8$ & $6 / 8$ \\
Line Bisection & 5 & $2 / 8$ & $8 / 8$ & $3 / 8$ & $7 / 8$ \\
Rep Drawing & 6 & $3 / 8$ & $8 / 8$ & $5 / 8$ & $8 / 8$ \\
Total & & 14 & 41 & 13 & 42 \\
\hline
\end{tabular}

with and without visual field deficits. For the patients without neglect, only one test (Letter Cancellation) discriminated between the patients with and without visual field deficits, although all scores were above the designated cut-off for neglect. The statistical comparisons are shown in table $4 \mathrm{~b}$.

Patients without neglect but with visual field deficits performed worse than controls on only one test (Letter Cancellation). Patients without neglect or visual field deficits were statistically indistinguishable from controls on all six tests. The comparisons are shown in table $4 \mathrm{c}$.

\section{Discussion}

Examination of the two neglect groups with $(\mathrm{N}+\mathrm{VFD}+)$ and without field deficits $(\mathrm{N}+$ VFD -) revealed no significant differences in the severity of their neglect. Thus VFDs do not appear to affect visuo-spatial performance adversely when the presence of neglect is controlled. As a group, the mean score for the neglect patients with VFDs was slightly (albeit non-significantly) better than that of neglect patients without VFDs. This unexpected finding has been reported in studies of other spatial tasks. Hécaen and Assal, ${ }^{31}$ who compared the effects of left and right sided lesions on a variety of visual constructional tasks, found that patients with left brain damage with VFDs scored significantly better than those with intact fields. In the group with right brain damage the inverse was observed, but failed to reach significance. Ogden, ${ }^{23}$ who expected sensory loss to exacerbate visual neglect, likewise failed to find any significant difference between severity of neglect in patients with and without VFD. The fact that some neglect patients with hemianopia score slightly better than those without VFD may be due to increased reliance on extra-geniculostriate pathways; persistent visual neglect may imply an additional dysfunction at the sub-cortical level of directed attentional mechanisms.

The tendency to confound the effects of visual field deficits with those of higher functional deficits, such as neglect, stems from the sensory based theories put forward to explain the latter. ${ }^{32}$ This conflation is not altogether surprising as most patients with visual neglect also have a visual field deficit. ${ }^{33}$ The association may be expected given that posterior cerebrovascular lesions typically damage areas of 
Table 4 Statistical analysis of the effects of neglect (with visual field deficits controlled) and of visual field deficits (with neglect controlled) on six tests; - = performance at ceiling

\begin{tabular}{|c|c|c|c|c|c|c|}
\hline \multirow[b]{2}{*}{ (a) } & \multicolumn{3}{|c|}{$V F D+N+$ versus $V F D+N-$} & \multicolumn{3}{|c|}{$V F D-N+$ versus $V F D-N-$} \\
\hline & $t$ & $D f$ & $p$ & $t$ & $D f$ & $p$ \\
\hline \multirow[t]{2}{*}{$\begin{array}{l}\text { Line Crossing } \\
\text { Letter Cancellation } \\
\text { Star Cancellation } \\
\text { Figure Copying } \\
\text { Line Bisection } \\
\text { Rep Drawing }\end{array}$} & $\begin{array}{l}1 \cdot 12 \\
3 \cdot 08 \\
3 \cdot 13 \\
2 \cdot 84 \\
3 \cdot 14 \\
2 \cdot 65\end{array}$ & $\begin{array}{l}7 \\
7 \\
8 \\
7 \\
7 \\
7\end{array}$ & $\begin{array}{l}\text { NS } \\
0.02 \\
0.02 \\
0.05 \\
0.02 \\
0.05\end{array}$ & $\begin{array}{l}3 \cdot 04 \\
4 \cdot 47 \\
2 \cdot 81 \\
2 \cdot 96 \\
2 \cdot 87 \\
1 \cdot 83\end{array}$ & $\begin{array}{l}7 \\
7 \\
7 \\
8 \\
8 \\
7\end{array}$ & $\begin{array}{l}0.02 \\
0.01 \\
0.05 \\
0.02 \\
0.05 \\
\text { NS }\end{array}$ \\
\hline & \multicolumn{3}{|c|}{$V F D+N+$ versus $V F D-N+$} & \multicolumn{3}{|c|}{$V F D+N-$ versus $V F D-N-$} \\
\hline (b) & $t$ & $D f$ & $p$ & $t$ & $D f$ & $p$ \\
\hline \multirow[t]{2}{*}{$\begin{array}{l}\text { Line Crossing } \\
\text { Letter Cancellation } \\
\text { Star Cancellation } \\
\text { Figure Copying } \\
\text { Line Bisection } \\
\text { Rep Drawing }\end{array}$} & $\begin{array}{l}1 \cdot 02 \\
0 \cdot 32 \\
0 \cdot 30 \\
0 \cdot 31 \\
0 \cdot 29 \\
0 \cdot 21\end{array}$ & $\begin{array}{l}13 \\
13 \\
13 \\
13 \\
13 \\
13\end{array}$ & $\begin{array}{l}\text { NS } \\
\text { NS } \\
\text { NS } \\
\text { NS } \\
\text { NS } \\
\text { NS }\end{array}$ & $\begin{array}{l}0.91 \\
2 \cdot 87 \\
1 \cdot 10 \\
0.61 \\
0.94 \\
-\end{array}$ & $\begin{array}{r}9 \\
13 \\
10 \\
13 \\
8 \\
-\end{array}$ & $\begin{array}{l}\text { NS } \\
0.02 \\
\text { NS } \\
\text { NS } \\
\text { NS } \\
-\end{array}$ \\
\hline & \multicolumn{3}{|c|}{$V F D+N-$ versus controls } & \multicolumn{3}{|c|}{$\underline{V F D}-\mathrm{N}-$ versus controls } \\
\hline (c) & $t$ & $D f$ & $p$ & $t$ & $D f$ & $p$ \\
\hline $\begin{array}{l}\text { Line Crossing } \\
\text { Letter Cancellation } \\
\text { Star Cancellation } \\
\text { Figure Copying } \\
\text { Line Bisection } \\
\text { Rep Drawing }\end{array}$ & $\begin{array}{l}1.37 \\
3.46 \\
1.79 \\
1.00 \\
0 \cdot 17 \\
-\end{array}$ & $\begin{array}{r}7 \\
13 \\
7 \\
7 \\
7 \\
-\end{array}$ & $\begin{array}{l}\text { NS } \\
0.01 \\
\text { NS } \\
\text { NS } \\
\text { NS } \\
-\end{array}$ & $\begin{array}{l}1.00 \\
0.27 \\
1.01 \\
1.53 \\
1.32 \\
-\end{array}$ & $\begin{array}{r}7 \\
13 \\
9 \\
7 \\
7 \\
-\end{array}$ & $\begin{array}{l}\text { NS } \\
\text { NS } \\
\text { NS } \\
\text { NS } \\
-\end{array}$ \\
\hline
\end{tabular}

visual cortex or the suprageniculate pathways. Furthermore, the predominantly lateralised nature of visual neglect is clearly consistent with an "infra-cognitive" explanation at the level of lateralised sensory loss. ${ }^{34}$ Indeed the motivation behind one of the first large scale studies of visual neglect focused on the difficulty of distinguishing "frank sensory deficits" from "associated spatial deficits". ${ }^{35}$ None the less, several types of evidence illustrate the differences between the two conditions. Although in acute cases, and/or patients with severe brain damage, the distinction is difficult to sustain, ${ }^{25}$ the phenomena are operationally quite distinct.

A visual field deficit refers to a sensory disturbance which occurs within the patient's visual field and is detected by asking the patient to fixate a central point while the observer introduces small test objects from the periphery. By contrast, visual neglect occurs in free vision and describes a spatial disorder that can be readily seen in spontaneous behaviour. Double dissociations are then observed between the two conditions; patients have been reported with florid visual neglect who are clearly not hemianopic ${ }^{22}$ and many hemianopic patients do not show visual neglect. ${ }^{2}$

Differences in the time course of recovery are also found between the two conditions. ${ }^{36}$ The experimental findings of Bisiach et $a^{32}$ and Ogden $^{37}$ demonstrate that neglect can persist despite providing the patient with continuous central viewing of a target that slowly moves behind a slit. The current proliferation of studies reporting neglect in visual imagery, ${ }^{38-40}$ also supports the case for the relative independence of visual neglect from merely retinopic correspondence. On these grounds, one might argue that visual field defects and visual neglect are functionally unrelated, and that their frequent co-occurrence should be interpreted as due to constraints of anatomical contiguity. Indeed, much of the thrust behind the early claims for a sensory explanation of visual neglect appears to rest with the misconception that confused spatial field with visual field. ${ }^{41}$ A recent report by Kooistra and Heilman $^{42}$ helps to resolve the confusion. Their patient appeared to manifest a visual field deficit when her eyes were directed straight ahead or to the left; but the defect abated when the eyes were directed towards right hemispace. The clear conclusion is that the patient showed hemispatial visual inattention rather than hemianopia. ${ }^{42}$

Finally, the clinical presentation of visual neglect is qualitatively distinct from that of VFD. The hemianopic patient appears able to incorporate the sensory impaired hemifield within his spatial awareness. Patients with neglect, on the other hand, fail to integrate stimuli in contralesional space; they appear unable to conceive, and therefore be aware of, both the existence of contralesional space and their omission of located stimuli.

This central and often characteristic aspect of florid neglect in otherwise well-oriented patients has been insufficiently developed in most discussions of the clinical presentation. Subjective lack of awareness militates against involvement and success in therapy programmes and readily translates into many of the problems and frustrations described by patients, their therapists and families. But the weight of evidence now strongly suggests that visual field deficits per se are neither a bar to good functional recovery nor a factor that exacerbates the severity and poor prognosis of visuo-spatial neglect.

This work was supported by the Chest, Heart and Stroke Association and by the Medical Research Council.

$1 \mathrm{Zihl} \mathrm{J}$. Cerebral disturbances of elementary visual functions. In: Brown J, ed. Neuropsychology of Visual Perception. London: Erlbaum, 1989:35-58.

2 Critchley M. The Parietal Lobes. New York: Hafner, 1953. 3 Meienberg $\mathrm{O}$, Harrer $\mathrm{M}$, Wehren $\mathrm{C}$. Oculographic diagnosis of hemineglect in patients with homonymous hemianopia. 
$J$ Neurol 1986;233:97-101

4 Ishiai $S$, Furukawa $T$, Tsukagoshi $H$. Eye fixation patterns in homonymous hemianopia and unilateral spatial neglect. Neuropsychologia 1987;25:675-9.

5 Girotti G, Casazza M, Musicco M, Avanzini G. Occulomotor disorders in cortical lesions in man: the role of unilateral neglect. Neuropsychologia 1983;21:543-53.

6 Dombovy ML, Sandok BA, Basford JR. Rehabilitation for stroke: a review. Stroke 1986;17:363-9.

7 Reding MJ, Potes E. Rehabilitation outcome following initial unilateral hemisphere stroke: life table analysis approach. Stroke 1988;19:1354-8.

8 Haerer AF. Visual field defects and the prognosis of stroke patients. Stroke 1973;4:163-8.

9 Feigenson JS, McDowell FW, Meese P, McCarthy ML Greenberg SD. Factors influencing outcome and length of stay in a stroke rehabilitation unit. Part 1. Stroke 1977; 8:651-6.

10 Wade DT, Skilbeck CE, Langton Hewer R. Predicting Barthal ADL score at 6 months after an acute stroke. Arch Phys Med Rehab 1983;64:24-8.

11 Henley S, Pettit S, Todd-Pokropek A, Tupper A. Who goes home? Predictive factors in stroke recovery. $J$ Neurol Neurosurg Psychiatry 1985;48:1-6.

12 Allen CM. Predicting the outcome of acute stroke; a prognostic score. J Neurol Neurosurg Psychiatry 1984;
47:475-80.

13 Fullerton KJ, McSherry D, Stout RW. Albert's test: a neglected test of perceptual neglect. Lancet 1986;i:430-2.

14 Kinsella G, Ford B. Hemi-inattention and the recovery patterns of stroke patients. Int J Rehab Med 1985;7:102-6.

15 Denes G, Semenza C, Stoppa E, Lis A. Unilateral spatial neglect and recovery from hemiplegia. Brain 1982;105: 543-52.

16 Wade DT, Langton Hewer R, Skilbeck CE, David RM. Stroke: a critical approach to diagnosis, treatment and management. London: Chapman and Hall, 1985.

17 Jongbloed L. Prediction of function after stroke: a critical review. Stroke 1986;17:765-76.

18 Johnston CW. Eye movements in visual hemi-neglect. In: Johnston CW, Pirozzolo FJ, eds. Neuropsychology of Eye Movements. London: Erlbaum, 1988.

19 Gainotti G, D'Erme P, Monteleone D, Silveri MC. Mechanisms of unilateral neglect in relation to laterality of cerebral lesions. Brain 1986;109:599-612.

20 Costa LD, Vaughan HG, Horwitz M, Ritler W. Patterns of behavioural deficit associated with visual spatial neglect. Cortex 1969;5:242-63.

21 Colombo A, De Renzi E, Faglioni P. The occurrence of visual neglect in patients with unilateral cerebral disease. Cortex 1976:12:221-31.

22 Vallar G, Perani D. The anatomy of unilateral neglect afte right hemisphere stroke lesions. A clinical/CT scan correlation study in man. Neuropsychologia 1986;24: 609-22.
23 Ogden J. Anterior-posterior hemispheric differences in the loci of lesions producing visual hemineglect. Brain and Cognition 1986;4:59-75.

24 Weintraub S, Mesulam M. Visual hemispatial inattention: stimulus parameters and exploratory strategies. $J$ Neurol Neurosurg Psychiatry 1988;51:1481-8.

25 Rubens A. Caloric stimulation and unilateral visual neglect. Neurology 1985;35:1019-24

26 Gouvier WD, Cottam G, Webster JS, Beissel GF, Wofford JD. Behavioral interventions with stroke patients for improving wheelchair navigation. International Journal of Clinical Neuropsychology 1986;6:186-90.

27 Wilson B, Cockburn J, Halligan PW. Behavioural Inattention Test. Titchfield, Hampshire: Thames Valley Test Company, 1987.

28 Nelson H. National Adult Reading Test. Windsor: NFERNelson, 1982 .

29 Albert M. A simple test of visual neglect. Neurology 1973;23:658-64.

30 Halligan PW, Marshall JC, Wade DT. Visuospatial neglect: underlying factors and test sensitivity. Lancet 1989;ii: 908-10.

31 Hécaen $\mathrm{H}$, Assal G. A comparison of construction deficits following right and left hemisphere lesions. Neuropsychologia 1970;8:289-304.

32 Bisiach E, Capitani E, Luzzatti C, Perani D. Brain and conscious representation of outside reality. Neuropsychologia 1981;19:543-51.

33 De Renzi E. Disorders of space exploration and cognition. New York: Wiley, 1982.

34 Bisiach E, Berti A, Vallar G. Analogical and logical disorders underlying unilateral neglect of space. In: Posner MI, Marin OSM, eds. Attention and Performance XI. London: Erlbaum, 1985:239-49.

35 Battersby WS, Bender MB, Pollack M, Kahn RL. Unilateral spatial agnosia (inattention) in patients with cerebral lesions. Brain 1956;79:68-93.

36 Hier DB, Mondlock J, Caplan LR. Recovery of behavioral abnormalities after right hemisphere stroke. Neurology $1983 ; 33: 345-50$

37 Ogden J. Contralesional neglect of constructed visual images in right and left brain-damaged patients. Neuropsychologia 1985;23:273-7.

38 Bisiach E, Luzzatti C. Unilateral neglect of constructed space. Cortex 1978;14:129-33.

39 Halsband V, Gruhn S, Ettlinger G. Unilateral spatial neglect and defective performance in one half of space. Int $J$ Neuroscience 1985;28:173-95.

40 Meador KJ, Loring DW, Bowers D, Heilman KM. Remote memory and neglect syndrome. Neurology 1987;37:522-6.

41 Jeannerod $M$ (ed.). Neurophysiological and neuropsychological aspects of spatial neglect. North-Holland: Elsevier, 1987.

42 Kooistra CA, Heilman KM. Hemispatial visual inattention masquerading as hemianopia. Neurology 1989;39:1125-7. 